\title{
CLINICAL TYPES OF SMALLPOX AS SEEN IN AN EPIDEMIC
}

\author{
Guilherme Rodrigues-DA-Silva, M.D. (Salvador) \\ Fellow in Epidemiology \\ S. Ivo Rabello, M.D. (Recife) \\ Fellow in Epidemiology \\ Instituto Adolfo Lutz, São Paulo, Brazil
}

Juan J. Angulo, M.D. (Havana)

Epidemiologist

THE clinical picture of smallpox has been the subject of numerous publications, some of which deserve special mention like the fundamental work of Ricketts and Byles (I910) and the studies of Marsden (1948) and of Dixon (1948). Dixon's report is outstanding because of the improved classification of clinical types proposed. The potentialities of this classification in smallpox studies became apparent during a sharply limited epidemic occurring in a semi-isolated borough of São Paulo City and they are remarked in the present paper.

\section{Clinical Material}

Collection of clinical data was aimed at classification of the symptomatology according to the types proposed by Dixon (1948). Twenty cases were seen while still sick and followed up, 12 of whom had been admitted to the Isolation Hospital 'Emilio Ribas'. Twenty-eight additional cases were examined soon after disappearance of the exanthem. From these patients fairly reliable data on symptomatology could retrospectively be obtained which were checked by cross-questioning, physical examination and inquiries among their relatives. The remainder of the 53 cases composing the epidemic were not seen and they are not included in this report. In an attempt to support clinical diagnosis with ætiological (laboratory) and epidemiological data, skin lesion material from eight cases was obtained for virus isolation (Downie and Dumbell, r947), blood was collected for antibody titration (Lederle Laboratories Division, 1954) from ten cases and 37 contacts, and information on previous smallpox, chickenpox and vaccination was obtained from each case.

Identification of the infection responsible for the epidemic could be established beyond any reasonable doubt through the following evidence: (a) Only variola virus was isolated and identified in skin lesion specimens and all the latter were positive; (b) the antibody response of cases and of household contacts indicated a recent infection by variola or vaccinia virus, and in all instances the previous exposure to these viruses hado occurred too long a time before for justifying the 3 . present, positive complement fixation; $(c)$ labora- $\omega_{\infty}$ tory confirmation of diagnosis was made in 16 out of the 53 cases in the epidemic; $(d)$ in 48 cases. diagnosis was established through standard clinical $\vec{A}$ and epidemiological criteria, while in the five cases 0 not seen the epidemiological data strongly sug-음 gested a variolous ætiology; $(e)$ no case was ob- served among the rather numerous household 3 contacts who had suffered from smallpox in the past, not even a variola sine eruptione; $(f)$ the majority of cases had suffered from chickenpox.

\section{Observations on Clinical Types}

The distribution of the cases studied among clinical types of smallpox is presented in Table $\mathrm{r}$. The 48 cases examined were classified as: Type $1, \stackrel{2}{2}$ 'purpura variolosa'; type 4 , 'benign confluent'; $\mathbb{Q}$ type 6, 'discrete'; type 7, 'mild'; type 8, $\overrightarrow{\vec{F}}$ 'abortive'; and type 9, 'variola sine eruptione'. 옥 Type 2, 'malignant confluent'; type 3, 'malignant semi-confluent', and type 5 , 'benign semi-confluent ' were not observed. Type 6, ' discrete', was the predominant clinical type $-68.7 \%$. of the cases.

Type 9, 'variola sine eruptione' cases, were classified as such when they showed a syndrome identical with that of the prodromal period of undoubted cases; its duration was similar and itso onset occurred after the same time interval. Finally, diagnosis of four cases of variola sine 0 eruptione was confirmed by serological tests whose significance was increased by a strongly suggestive vaccinal history. All four cases showed a $1: 64$ N titre in the complement fixation test while the N last vaccination had been made more than I, 20, 20 and 40 years before, respectively. Symp-o tomatology of type 9 cases was apparently not milder than that of the prodromal period in $\stackrel{?}{+}$ patients with exanthem and the duration of the 0 corresponding periods was essentially the same.

The age distribution of clinical types is also 
TABLE I

Distribution of 48 Smallpox Cases Among Clinical Types

\begin{tabular}{|c|c|c|c|c|c|c|c|c|c|c|c|c|}
\hline \multirow{2}{*}{\multicolumn{5}{|c|}{ Age-group (Years) }} & \multirow{2}{*}{\multicolumn{6}{|c|}{ Clinical Types* }} & \multicolumn{2}{|c|}{ Total } \\
\hline & & & & & & & & & & & No. & $\%$ \\
\hline \multirow[b]{2}{*}{$\begin{array}{l}0-7 \\
8-15 \\
16+\end{array}$} & \multirow[b]{2}{*}{$\begin{array}{l}\cdots \\
\cdots \\
\cdots\end{array}$} & \multirow[b]{2}{*}{$\begin{array}{l}\ldots \\
\cdots \\
\ldots\end{array}$} & \multirow[b]{2}{*}{$\begin{array}{l}\cdots \\
\therefore\end{array}$} & \multirow[b]{2}{*}{$\begin{array}{l}\cdots \\
\cdots \\
\cdots\end{array}$} & $\mathbf{I}$ & 4 & 6 & 7 & 8 & 9 & & \\
\hline & & & & & I & $\begin{array}{l}2 \\
1\end{array}$ & $\begin{array}{r}21 \\
7 \\
5\end{array}$ & I & $\begin{array}{l}2 \\
\text { I } \\
\text { I }\end{array}$ & $\begin{array}{l}\text { I } \\
2 \\
3\end{array}$ & $\begin{array}{l}27 \\
11 \\
10\end{array}$ & $\begin{array}{l}56.3 \\
22.9 \\
20.8\end{array}$ \\
\hline \multicolumn{2}{|c|}{ Total Number } & . & .. & .. & I & 3 & 33 & I & 4 & 6 & 48 & \\
\hline$\%$ & .. & .. & .. & $\ldots$ & 2.1 & 6.3 & 68.7 & 2.1 & 8.3 & I2.5 & & 100.0 \\
\hline
\end{tabular}

*According to Dixon's classification (Dixon, 1948)

found in Table I. Type 6, ' discrete' smallpox, predominated in the pre-school age-group, 0-7 years, while the more benign clinical types 8 and 9 were more frequent among individuals 8 or more years of age. This fact apparently contradicts the known higher severity of infection among older age-groups. However, the vaccinal history explains this finding since most school-age and adult cases had a previous vaccination while most of the pre-school cases were not vaccinated.

TABLE 2

Distribution of Clinical Types in Relation to IMMUNITY*

\begin{tabular}{|c|c|c|c|c|}
\hline \multirow{2}{*}{$\begin{array}{l}\text { Clinical } \\
\text { Type }\end{array}$} & \multirow{2}{*}{$\begin{array}{c}\text { Without } \\
\text { Vaccination } f\end{array}$} & \multicolumn{3}{|c|}{$\begin{array}{c}\text { Years after } \\
\text { successful vaccination }\end{array}$} \\
\hline & & $5+$ & $I-5$ & $0-1$ \\
\hline $\mathbf{I}$ & $\mathbf{I}$ & & & \\
\hline 4 & 3 & & & \\
\hline 6 & 30 & 2 & I & \\
\hline 7 & $\mathbf{I}$ & & & \\
\hline 8 & $\mathbf{I}$ & I & I & I \\
\hline 9 & & 3 & 3 & \\
\hline
\end{tabular}

* The vaccinal history of five cases was unknown.

$\uparrow$ After Dixon's (1948) classification.

$\ddagger$ Including those unsuccessfully vaccinated.

The only patient showing type I, purpura variolosa, was a 30-year-old Negro woman. This case exhibited a striking characteristic. The upper half of the body showed numerous large purpuric spots of irregular shape and well differentiated contour. Large areas of skin-sloughing up to $12 \times 8 \mathrm{~cm}$. in size were observed on the face, shoulders, chest, abdomen, back and buttocks. On the upper half of the body pocks were only seen on the face, chest and palms, but these lesions were ill-defined and very scanty except in the palms, where they were rather numerous although very small. On the other hand, the lower half of the body exhibited a pock-exanthem with no purpuric lesion. A centrifugal distribution of pocks was apparent and these lesions were better defined on the legs and feet. Pocks were velvety, rather flat, clear, and apparently did not become pustules. The exanthem on the lower half of the body was rather profuse although confluence of pocks was only noticed in a few places. Pocks were rare on the soles of the feet. The onset and disappearance of the purpuric rash coincided with the pock-exanthem. Diagnosis of this striking case was confirmed by isolation and identification of variola virus from two specimens, each consisting of pooled content of several vesicles. Besides, the patient had never had smallpox or vaccination 'take' and two cases occurred in the same household before hers and one case thereafter. The illness began with myalgia and headache to which were added chills and intense fever, all lasting three days and disappearing at the onset of the exanthem. The latter was manifest first on the abdomen and face; it then appeared on the legs and later on the rest of the body. Intense toxæmia and mental symptoms like clouding of consciousness and anxiety were observed in this case who, incidentally, recovered with no other complication than a palpebral cellulitis. During convalescence there was intense desquamation, leaving pinkish areas which contrasted with the normal colour of the patient's skin. Bleeding time, coagulation time, Rumpel-Leede (Hess) test and platelet count were negative for hæmorrhagic diatheses, but these examinations were, unfortunately, made after disappearance of the exanthem.

The epidemic was characterized by a wellmarked predominance of benign clinical types, in such a way that $3^{8}$ out of the 42 cases whose exanthem was classified could be identified as cases of the so-called alastrim or variola minor 
(Tables I and 2). This is the usual pattern of smallpox epidemics in the state of São Paulo and, apparently, in the rest of Brazil. Clinicians with long experience in smallpox have noticed that several decades ago admissions to the Isolation Hospital 'Emilio Ribas' of São Paulo City included a strikingly larger proportion of severe cases (Pereira-Barreto).

\section{Comment}

Dixon's classification permits standardizing clinical features which in turn allows a quantitative comparison between epidemics as well as between individual cases. Incidentally, comparison of the clinical type of an infecting case with that of his infected contacts has a direct bearing on a much discussed subject, namely, the relationships between smallpox and the so-called alastrim. The clinical findings made in the present study as well as the epidemiological and laboratory data do not support the pretended separation of alastrim and smallpox as two different diseases (Jorge, 1924; Marsden, 1948). Quite on the contrary, the evidence obtained supports, without being conclusive, the contrary thesis, that is, the identity of alastrim and 'true' smallpox. The controversy on this point has lasted several decades and, apparently, has not been settled. The remarks on the significance of the data collected in the present study were derived from the following facts and arguments:

(a) Dixon's classification of clinical types, unlike the classifications found in textbooks and treatises, represents a logical arrangement where a gradation in intensity is ably presented. This classification was the resultant of a rather large body of accurate field observations and its reproducibility has been confirmed in the clinical and epidemiological experience of the present authors who have observed hundreds of smallpox cases in hospitals and in the field.

(b) A gradation in the severity of syndromes and isolated manifestations was evident in the whole series of cases in the sharply limited epidemic studied. This gradation was particularly evident in the intra-household outbreaks observed during the study of cases and which actually composed the epidemic. In most households, several cases occurred at intervals, suggesting contagion from one index case, and these secondary cases showed differences in the severity of their clinical pictures which at times were strikingly marked, not only among themselves but also in relation to the index case. In this regard, Dixon's comparison of the clinical type of 13 mothers with the type of their infants under $I$ year of age deserves mention. While three mothers showed clinical types proper of variola major, their babies ex- hibited alastrim-like eruptions. Three other babies气̊ presented a severe clinical picture while their 3 mothers showed mild syndromes.

(c) The epidemiological data disclosed a chain $\subseteq$ of contagion stemming from the two introducers $\overrightarrow{\vec{F}}$ of infection in the borough and giving rise to? widely varying clinical pictures. Incidentally, 등 none of the introducers showed a picture of $\frac{\bar{c}}{\bar{c}}$ variola major.

(d) The case of type I, purpura variolosa, whoळ clinically was a typical case of variola major: (variola vera), belonged to an intra-household outbreak where three cases preceded and another ${ }_{-}^{-}$ one followed hers. None of these contact cases $\vec{\omega}$ was of variola major, particularly that apparently infected by her. The latter contact exhibited $x 0$ type 8 , ' abortive' variola.

(e) The relationship of variola sine eruptione to previous vaccination (Table 2). In this regard, four of these six cases had their diagnoses con-.V firmed by laboratory evidence.

(f) The relationship between vaccination and ' mild' and ' abortive' eruptions (types 7 and 8 )..$?$ One out of the I I cases exhibiting type 7,8 or $9 \vec{z}$ was unvaccinated, while 34 of the 37 cases show-w ing types $I, 4$ or 6 were unvaccinated (Table 2). $\frac{\bar{\alpha}}{\sigma}$ A very similar relationship between vaccination. and clinical type was noticed by Dixon (1948. Incidentally, many of Dixon's cases were typical of variola major and the epidemic cannot be cos sidered as an outbreak of alastrim.

$(g)$ The behaviour, on isolation and serialo passaging on the chick embryo chorioallantois, of the virus strain recovered from the case of pur- $\mathbb{\AA}$ pura variolosa was not different from the behaviour $\overrightarrow{\vec{B}}$ of the strains isolated from cases clinically belong-을 ing to the so-called alastrim nor has a difference been noticed when working with other strains ino this laboratory.

\section{Observations on Individual Signs and Symptoms}

The cases studied exhibited a definitely biphasicô clinical picture in which the first phase consisted of systemic manifestations while the second phase corresponded to an exanthem. Table 3 sum- $>$ marizes the characteristics of the prodromic period을. in 46 patients showing, at the same time, the frequency of each individual sign or symptom. Sudden onset was noted in $93 \%$ of cases. Headache, $N$ chills and/or fever composed the initial symp-N tomatology in most patients. Fever was noted ing all cases during the prodromal period and it waso usually preceded by chills, while the temperature rise was rapid, reaching suddenly $39^{\circ}$ or $40^{\circ} \mathrm{C} . ?$ $\left(102^{\circ}-104^{\circ} \mathrm{F}\right.$.). Fever was of the continuous type, had a duration of three days (three days \pm 0.5 ) and usually disappeared on the first day of the 
exanthem. Prostration, headache, anorexia, back pains, general malaise, chills and vomiting were the other more common symptoms and signs during the prodromal period (Table 3). Symptoms related to the digestive system, such as nausea, vomiting, diffuse abdominal pain and diarrhœa, were observed among patients not older than 8 years, except for one, a $3^{8-y e a r-o l d ~ c a s e . ~}$

\section{TABLE 3}

Prevalence of Signs and Symptoms Composing the Prodromic Period among 46 Cases of Smallpox*

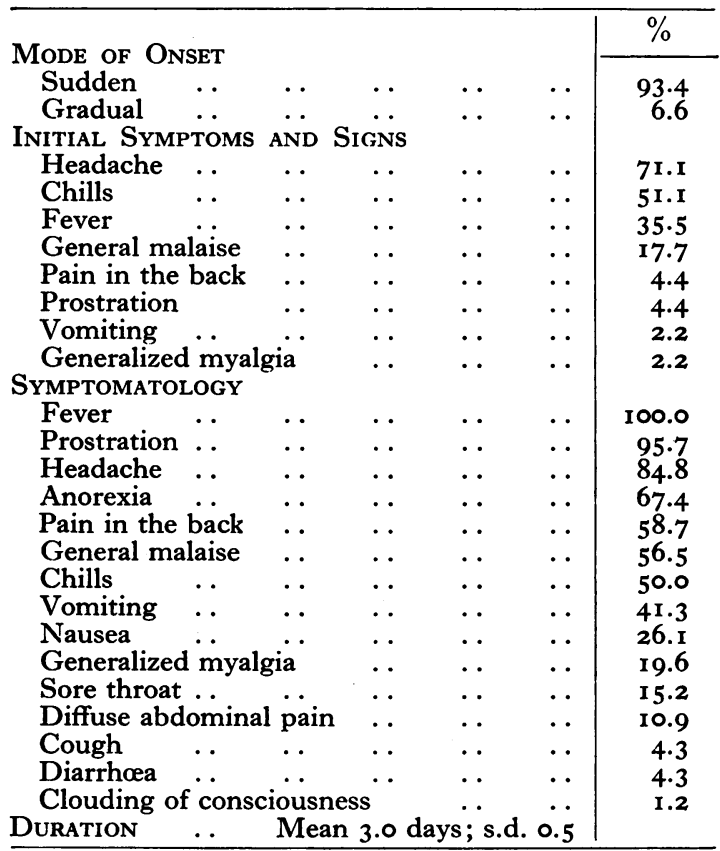

* Data from two other cases were incomplete.

The onset of the exanthem coincided with disappearance of systemic manifestations in all cases. Table 4 summarizes the main characteristics of the exanthemic phase in 42 cases. In the majority of patients the exanthem first appeared on the face. In five cases observed since onset of the prodromic period, it was possible to follow the classical course of macule, papule, crust and scar. In the first day of the rash macules and papules were observed, and from the second day on vesicles became apparent. The latter lasted three or four days and then pus was apparent. Duration of pustules was approximately two weeks when crusts ensued. Regional monomorphism of skin lesions was observed in all but one case. Umbilication of pustules was rarely observed.

The body distribution of the exanthem was definitely centrifugal in $79 \%$ of the 42 cases whose exanthem was classified. In all but two of these
TABLE 4

Main Clinical Characteristics of the Exanthem in 42 Smallpox Cases*

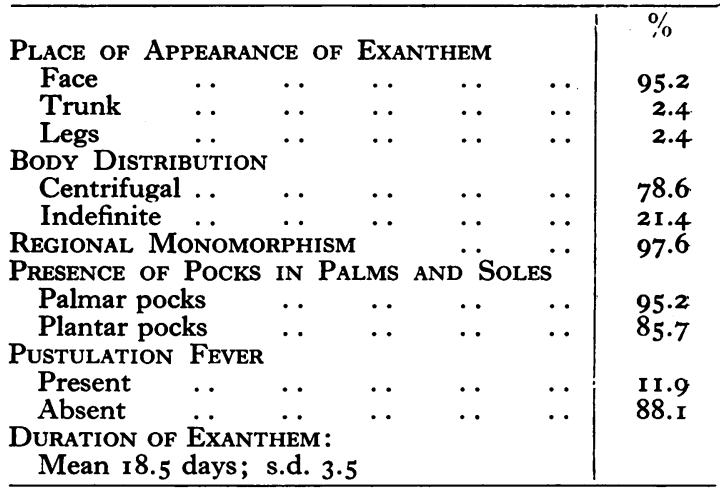

*Six of the 48 patients examinated exhibited no eruption.

cases pocks were found in the palms, while plantar pocks were not observed in six patients. The mean duration of the exanthem, from onset to total shedding of crusts, was 18.5 days \pm 3.5 .

The pustulation fever, uncommon in alastrim cases, occurred in only five cases ( $12 \%$ ), from the third to the fifth day. It is possible, however, that this was not the true frequency since many cases were nursed at home where temperature was not efficiently recorded. Severe toxæmia accompanying the eruption, typical of variola major, was noticed only in the case of purpura variolosa.

Mortality was nil, all patients recovering, including the case of purpura variolosa. The only complication observed was palpebral cellulitis resulting from secondary infection which appeared in the latter case. No antibiotic was employed in the cases studied. Treatment consisted of symptomatic medication and local measures protective of skin lesions.

\section{Summary}

Dixon's classification of the clinical types of smallpox was employed in the study of a sharply limited epidemic occurring in a semi-isolated borough of São Paulo City. Observations are made on the advantages of this classification in smallpox studies since it allows comparison, on a quantitative basis, between epidemics as well as between individual cases. The identity of alastrim and smallpox is discussed in the light of the clinical and epidemiological findings, particularly the relationship between vaccination and clinical type and the comparison between the clinical type of the infecting case and that of his infected contacts. The prevalence of relevant signs and symptoms of smallpox in the study group is presented. 


\section{REFERENCES}

Dixon, C. W. (1948): Smallpox in Tripolitania, 1946; Epidemiological and Clinical Study of 500 Cases, including Trials of Penicillin Treatment, f. Hyg. (Lond.), 46, $35 \mathrm{I}$.

Downie, A. W., and Dumbelt, K. R. (I947): Isolation and Cultivation of Variola Virus on Chorio-allantois of Chick Embryos, $\mathscr{f}$. Path. Bact., 69 , 189.

JoRGE, R. (1924): Alastrim and Variola, Lancet, ii, I31 7 ; ii, 1366.

Lederle Laboratories Division, A.C.C. (1954): ' Rickettsial and Viral Antigens ', Leaflet 10 M-10-54, New York.

MARSDEN, J. P. (1948): Variola Minor, Bull. Hyg. (Lond.), 23, 735.

Pereira-Barreto, L.: personal communication.

Ricketts, T. F., and Byles, J. B. (I910): 'The Diagnosis of Smallpox', New York: Funk and Wagnalls. 